\title{
Jean-Paul Marechal - CHINE/USA : le climat en jeu - Éditions Choiseul (2011), 114 pages
}

\section{Thierry Pouch}

\section{(2) OpenEdition}

1 Journals

Édition électronique

URL : http://journals.openedition.org/economierurale/3579

DOI : 10.4000/economierurale.3579

ISSN : 2105-2581

Éditeur

Société Française d'Économie Rurale (SFER)

\section{Édition imprimée}

Date de publication : 30 juillet 2012

Pagination : 216-217

ISSN : 0013-0559

\section{Référence électronique}

Thierry Pouch, « Jean-Paul Marechal - CHINE/USA : le climat en jeu - Éditions Choiseul (2011),

114 pages », Économie rurale [En ligne], 330-331 I juillet-septembre 2012, mis en ligne le 30 juillet 2014, consulté le 23 septembre 2020. URL : http://journals.openedition.org/economierurale/3579 ; DOI :

https://doi.org/10.4000/economierurale.3579 
Jean-Paul Maréchal

\section{Chine/USA : le climat en jeu}

Éditions Choiseul, 2011, 114 pages

D eux raisons principales motiveront le lecteur à ouvrir et à lire cet ouvrage réalisé par Jean-Paul Maréchal, économiste et enseignant-chercheur à l'Université de Rennes 2 , spécialiste entre autres domaines de l'économie de l'environnement. La première tient au fait que le réchauffement climatique exercera des répercussions de première importance sur l'agriculture, notamment en matière de localisation des productions agricoles. Cette probable reconfiguration de la production agricole mondiale est par ailleurs porteuse de migrations de populations, lesquelles ont d'ailleurs déjà commencé à se produire. La seconde raison a trait aux difficultés qu'éprouvent les nations à s'entendre sur les modalités d'une régulation du climat dans le sens d'une réduction des gaz à effets de serre. À ce titre, les conférences et autres sommets internationaux ont montré les limites de l'exercice multilatéral en ce domaine. Que ce soit à Copenhague en 2009, à Cancún en 2010 ou plus récemment à Durban, les avancées restent timides dès lors qu'il s'agit de mettre d'accord pays industrialisés et pays émergents sur une politique climatique multilatérale dont la visée serait de contenir puis d'inverser le processus du réchauffement climatique, ou, dit autrement, de se projeter dans un après-Kyoto. Et pourtant, le livre de J.-P. Maréchal nous I'indique d'emblée, le climat est devenu I'un " des défis majeurs auxquels I'humanité devra répondre au cours de ce siècle "'.

La démarche de l'ouvrage est de se positionner sur un registre non pas multilatéral mais bilatéral. L'analyse du changement climatique et des politiques possibles

1. In page 9 . à mener concerne certes tous les pays, mais plus spécifiquement les États-Unis et la Chine, c'est-à-dire les deux premières puissances mondiales de ce $x X^{e}$ siècle. L'auteur justifie son option en prenant à son compte l'argument développé par Chris Patten, selon lequel I'Union européenne serait économiquement et politiquement déclassée au cours de ce siècle, induisant du même coup un comportement de suiveur dans les négociations internationales, et une incapacité à peser sur le cours de ces discussions traitant du climat. Mais il revient fort justement, données chiffrées à l'appui, sur ce qui fait la puissance économique de ces deux nations. On peut ici toutefois s'interroger sur l'absence de I'Inde qui, manifestement, en tant qu'économie émergente, occupe une position de plus en plus importante dans les affaires du monde, ainsi qu'en témoignent la vision et les propositions qu'elle a défendues d'une part à l'OMC en 2008 dans le cycle de Doha, et plus récemment à Durban lors du sommet sur le climat.

Dans un premier chapitre, l'auteur revient sur le poids des deux économies américaine et chinoise dans la production des gaz à effets de serre (GES), soit $19 \%$ pour la première et un peu plus de $22 \%$ pour la seconde (on notera que l'ouvrage est bien documenté en statistiques, ainsi qu'en références bibliographiques). Le contenu de ce chapitre est essentiellement quantitatif et fort bien documenté, permettant au lecteur de se faire une idée des conséquences qu'engendrent les activités industrielles de ces deux pays sur le climat. S'appuyant sur les projections chiffrées rendues publiques par l'Agence Internationale de l'Énergie (AIE), l'auteur indique que, à l'horizon 2030, ce sont les pays non membres de l'OCDE qui émettront la quasi-totalité des GES, dont les trois-quarts proviendraient de la Chine.

Cette perspective conduit J.-P. Maréchal à mettre au jour un dilemme bien connu des économistes, le " dilemme du prisonnier ", et à démontrer en quoi les 
blocages sont intenses lors des sommets internationaux, puisque les pays émergents arguent que la croissance est pour eux le seul moyen de réduire et de sortir de la pauvreté. De même, il est indiqué que l'idée d'une justice climatique, dont l'objectif reviendrait à partager le fardeau du changement climatique, suscite de nombreuses critiques non seulement au sein de la profession des économistes, mais surtout entre les pays industrialisés et émergents.

II n'est par conséquent guère surprenant que l'auteur tire un enseignement assez négatif de l'état actuel du climat, poussant du même coup le raisonnement en effectuant une incursion dans le champ de la géo-économie, les blocages caractérisant les négociations illustrant selon lui un climat de guerre entre les principaux producteurs de GES. Car dans la prise de conscience de la dégradation du climat et des conséquences probables sur les activités humaines, l'auteur constate que les deux principales puissances économiques mondiales ont développé depuis plusieurs années les productions d'énergies renouvelables, dont ils sont leaders. Sauf que, et c'est sans doute le chapitre le plus intéressant du livre, c'est moins pour préserver le climat que pour se constituer en puissance économique dominante, ou pour la préserver, que la Chine et les États-Unis investissent des milliards de yuans et de dollars dans les énergies renouvelables. L'affirmation des technologies vertes dans ces deux pays est motivée pour la Chine par la construction d'un leadership sur les affaires du monde, que ce soit en matière industrielle (coûts de production réduits grâce à l'énergie solaire), la « protection du marché intérieur (éolien) " ${ }^{2}$, ou encore dans le domaine de l'espionnage industriel. Dans la mesure où les États-Unis entendent poursuivre leurs propres recherches dans les technologies vertes l'auteur illustre sa démonstration de nombreuses citations de Barack Obama afin de préserver la sécurité du territoire

2. In page 7 . américain, il s'ensuit que le réchauffement climatique et ses solutions se transforment en réalité en une bataille de géants économiques. J.-P. Maréchal nous fait ainsi prendre conscience que l'issue souhaitée à la crise climatique qui vient ne surgira nullement d'un accord multilatéral, d'une structure de gouvernance réunissant les meilleures volontés, mais bien de projets nationaux aboutissant à une coopération internationale. II reviendra sans doute au G2 formé par la Chine et les États-Unis, de donner l'impulsion pour atteindre un degré élevé de coopération.

Une fois le livre refermé, le lecteur sera en mesure de mieux comprendre les enjeux du réchauffement climatique, ainsi que les rivalités géoéconomiques qui structurent les négociations internationales, et qui empêchent pour le moment tout accord à l'échelle mondiale. La crise climatique en voie de formation doit donc être interprétée en termes d'économie politique internationale. Peut-on pour autant se limiter aux seules nations, et parmi elles les deux plus importantes, pour saisir les enjeux du climat ? N'aurait-il pas été également opportun d'insérer le poids des firmes multinationales, véritables centres de décision économique mondiaux, dans l'analyse que suggère J.-P. Maréchal, afin de mettre en relief les jeux d'influence qui s'exercent sur les États ? De même, n'était-il pas envisageable de se pencher sur la capacité de résistance et sur la force de proposition des organisations non gouvernementales, ou encore sur l'ingéniosité politique de petits pays ou groupes de pays pour bâtir une ou des issues ? Cela aurait sans doute dépassé l'intention première de l'auteur, qui était de montrer, et de ce point de vue il a réussi, que derrière l'urgence à dégager un accord multilatéral, se dissimulent des rivalités étatiques portées par les États-Unis et la Chine.

Thierry POUCH

APCA PEPA et Université de Reims Champagne Ardenne, Laboratoire REGARDS 